\title{
Preparation of thermosensitive PNIPAm-based copolymer coated cytodex 3 microcarriers for efficient non-enzymatic cell harvesting during 3D culturing
}

\author{
Haile Darge ${ }^{1}$, Shun-Hao Chuang ${ }^{1}$, Juin-Yih Lai ${ }^{1}$, Shuian-Yin Lin $^{2}$, and Hsieh-Chih Tsai ${ }^{1}$ \\ ${ }^{1}$ National Taiwan University of Science and Technology \\ ${ }^{2}$ Industrial Technology Research Institute
}

March 24, 2021

\begin{abstract}
Enzymatic detachment of cells might damage important features of cells and could affect subsequent function of cells in various applications. Therefore, non-enzymatic cell detachment using thermosensitive polymer matrix is necessary for maintaining cell quality after harvesting. In this study, we synthesized thermosensitive PNIPAm-co-AAc-b-PS and PNIPAm-co-AAm-b-PS copolymers and LCST was tuned near to body temperature. Then, polymer solutions ( $5 \% \mathrm{w} / \mathrm{v}, 10 \% \mathrm{w} / \mathrm{v}$, and $20 \% \mathrm{w} / \mathrm{v})$ were spin coated to prepare films for cell adhesion and thermal-induced cell detachment. The apha-step analysis and SEM image of the films suggested that the thickness of the films depends on the molecular weight and concentration which ranged from $206 \mathrm{~nm}$ to $1330 \mathrm{~nm}$ for PNIPAm-co-AAc-b-PS and $97.5 \mathrm{~nm}$ to $497 \mathrm{~nm}$ for PNIPAm-co-AAm-b-PS. The contact angles of the films verified that the polymer surface was moderately hydrophilic at $37^{\circ} \mathrm{C}$. From cell attachment and detachment studies, RAW264.7 cells, were convincingly proliferated on the films to a confluent of $>80 \%$ within 48 days. However, relatively more cells were grown on PNIPAm-co-AAm-b-PS $(5 \% \mathrm{w} / \mathrm{v})$ films and thermal-induced cell detachment was more abundant in this formulation. As a result, commercial cytodex 3 microcarrier was coated with PNIPAm-co-AAm-b-PS (5\%w/v) and interestingly enhanced cell detachment with preserved potential of recovery was observed at low temperature during 3D culturing. Thus, surface modification of microcarriers with PNIPAm-co-AAm-b-PS could be vital strategy for non-enzymatic cell dissociation and able to achieve adequate number of cells with maximum cell viability, and functionality for various cell-based applications. Keywords: surface coated microcarriers; thermosensitive polymer; non-enzymatic cell detachment
\end{abstract}

Preparation of thermosensitive PNIPAm-based copolymer coated cytodex 3 microcarriers for efficient non-enzymatic cell harvesting during 3D culturing

Haile Fentahun Darge ${ }^{1,2}$ Shun-Hao Chuang ${ }^{1}$, Juin-Yih Lai ${ }^{1,2,3}$, Shuian-Yin Lin ${ }^{4},{ }^{*}$ and Hsieh-Chih Tsai ${ }^{1,2,3 *}$

1. Graduate Institute of Applied Science and Technology, National Taiwan University of Science and Technology, Taipei 106, Taiwan

2. Advanced Membrane Materials Center, National Taiwan University of Science and Technology, Taipei 106, Taiwan

3. R\&D Center for Membrane Technology, Chung Yuan Christian University, Chungli, Taoyuan 320, Taiwan

4. Biomedical Technology and Device Research Center, Industrial Technology Research Institute, Hsinchu 310, Taiwan

Authors to whom correspondence should be addressed

* Correspondence: Lilias@itri.org.tw (S.-Y. Lin); h.c.tsai@mail.ntust.edu.tw (H.-C. Tsai); 


\begin{abstract}
Enzymatic detachment of cells might damage important features of cells and could affect subsequent function of cells in various applications. Therefore, non-enzymatic cell detachment using thermosensitive polymer matrix is necessary for maintaining cell quality after harvesting. In this study, we synthesized thermosensitive PNIPAm- $c o$-AAc- $b$-PS and PNIPAm- $c o-A A m-b$-PS copolymers and LCST was tuned near to body temperature. Then, polymer solutions $(5 \% \mathrm{w} / \mathrm{v}, 10 \% \mathrm{w} / \mathrm{v}$, and $20 \% \mathrm{w} / \mathrm{v})$ were spin coated to prepare films for cell adhesion and thermal-induced cell detachment. The apha-step analysis and SEM image of the films suggested that the thickness of the films depends on the molecular weight and concentration which ranged from $206 \mathrm{~nm}$ to $1330 \mathrm{~nm}$ for PNIPAm- $c o$-AAc- $b$-PS and $97.5 \mathrm{~nm}$ to $497 \mathrm{~nm}$ for PNIPAm- $c o$-AAm- $b$-PS. The contact angles of the films verified that the polymer surface was moderately hydrophilic at $37^{\circ} \mathrm{C}$. From cell attachment and detachment studies, RAW264.7 cells, were convincingly proliferated on the films to a confluent of $>80 \%$ within 48 days. However, relatively more cells were grown on PNIPAm-co -AAm- $b$-PS $(5 \% \mathrm{w} / \mathrm{v})$ films and thermal-induced cell detachment was more abundant in this formulation. As a result, commercial cytodex 3 microcarrier was coated with PNIPAm-co-AAm- $b$-PS (5\%w/v) and interestingly enhanced cell detachment with preserved potential of recovery was observed at low temperature during $3 \mathrm{D}$ culturing.
\end{abstract}

Thus, surface modification of microcarriers with PNIPAm- $c o$-AAm- $b$-PS could be vital strategy for nonenzymatic cell dissociation and able to achieve adequate number of cells with maximum cell viability, and functionality for various cell-based applications.

Keywords : surface coated microcarriers; thermosensitive polymer; non-enzymatic cell detachment

\title{
Introduction
}

Maintaining adequate number of cells with preserved functionality and potency is the major challenge of cell culturing and significantly influence the subsequent outcomes in different medical applications such as cell therapy, tissue engineering, and vaccine production. In this regard, microcarrier-based cell culture has been realized as a propitious method for achieving high cell density by providing large surface-to-volume ratio in a suspension culture system (3D) compared to conventional planar culture (2D) for the growth of anchoragedependent cells. This also advantageous to overcome several hindrances encountered in conventional culture system, including requirement of large space and amount of culture media, heterogeneity of $\mathrm{pH}$ and nutrient concentration in the medium and inefficient exchange of gas, nutrients, and metabolites (C. Li, Qian, Zhao, Yin, \& Li, 2016; YekrangSafakar et al., 2018).

However, attachment and detachment of cells to and from microcarriers are basic concerns that determined the final cell productivity and quality. In this regard, the surface and size of microcarriers play important role for efficient cellular attachment and harvesting maximum yield of cell recovery while maintaining cell viability, potency, and functionality with respect to the final applications. Particularly, for the advent of tissue engineering and cell therapy in which cells are the final product themselves, a reliable strategy of cell harvesting should be chosen in a way to maximize cell recovery while preserving important cell features and functionalities(S. Derakhti, S. H. Safiabadi-Tali, G. Amoabediny, \& M. Sheikhpour, 2019; A. C. Tsai, R. Jeske, X. Chen, X. Yuan, \& Y. Li, 2020).

Although the typical enzymatic detachment method has been used for a wide range of cells and microcarriers, the harmful nature of enzymes on cells such as disrupting the structure of plasma membrane and a prolonged exposure of cells to enzymes inhibits cell growth and alters their indispensable characteristic (Tamura, Kobayashi, Yamato, \& Okano, 2012). Thus, recently a non-enzymatic method such as mechanical forces, development of degradable microcarriers, and incorporation of thermosensitive or cleavable materials onto the surface of microcarriers are among the alternative strategies which have been of great interest to researchers.

Thermally induced detachment of cells from microcarriers has been reported to better preserve cell characteristics and functionality compared to the proteolytic enzyme induced cell detachment methods (trypsinization). For instance, thermally induced detached hBM-MSCs and CHO-K1 cells had comparatively lower cell death 
and apoptosis with better reattachment ability and secretion of functional proteins(Tamura, Nishi, et al., 2012; H. S. Yang, Jeon, Bhang, Lee, \& Kim, 2010). As a result, it is appeared as an attractive non-invasive method for the detachment of cells from microcarriers. In this technique, a thermo-responsive material is grafted on the outermost surface of microcarrier which allows for harvesting cells with decreasing temperature below the low critical solution temperature (LCST). So far, various PNIPAAm-grafted microcarriers of different materials such as dextran, polystyrene (PS), silica, alginate, and glass have been fabricated (Hanga \& Holdich, 2014; Park, Nabae, Surapati, Hayakawa, \& Kakimoto, 2013; Song et al., 2016).

In this study, poly(N-isopropylacrylamide) (PNIPAm) was copolymerized with acrylic acid (AAc) or acrylamide (AAm) and then further polymerized with styrene to prepare poly (NIPAm-co -AAc)- $b$ polystyrene (PNIPAm- $c o-A A c-b$-PS) and poly (NIPAm- $c o$-AAm)- $b$-polystyrene (PNIPAm- $c o-A A m-b$ -PS), respectively. The incorporation of hydrophilic AAc and AAm could improve the LCST behavior of PNIPAm towards body temperature and enhanced cell adhesion by creating charged surface as well. Polystyrene could also increase the coating efficiency of the copolymer on commercial Cytodex 3 microcarrier through hydrophobic interaction. Thus, the commercial Cytodex 3 microcarrier was coated with these copolymers for efficient cell attachment and detachment in response to temperature change during 3D culturing. Because temperature triggered reversible hydrophobic to hydrophilic phase transition of the thermosensitive copolymers (PNIPAm- $c o$-AAc- $b$-PS and PNIPAm- $c o$-AAm- $b$-PS) promote cell adhesion and detachment, respectively (Kumashiro, Yamato, \& Okano, 2010; N. Li et al., 2021; Sakulaue et al., 2018). The presence of repeating hydrophilic amide and hydrophobic isopropyl groups in PNIPAm chains allowed the copolymers to undergo reversible conformational change with temperature alterations in aqueous environments. When the temperature is above the LCST, the copolymer chains form a compacted globule form which is suitable for cell adhesion, while under the LCST, they acquire a swelled shape which causes cell detachment from the surface (scheme 1 ) (Kim, Witt, Oswald, \& Tarantola, 2020; Nagase, Yamato, Kanazawa, \& Okano, 2018; Patel \& Zhang, 2013). Moreover, PNIPAAm has been chosen due to its quick phase transition and its LCST is near physiological temperature (Higuchi et al., 2014). So herein, RAW264.7 cells were thoroughly grown on polymer films as well as polymer coated cytodex 3 microcarriers at physiological temperature and successfully dissociated with lowering the temperature. Interestingly, temperature induced cell detachment was relatively abundant on PNIPAm- $c o-\mathrm{AAm}-b$-PS $(5 \% \mathrm{w} / \mathrm{v})$ coated Cytodex 3 microcarriers as well as the polymer films fabricated from PNIPAm- $c o-A A m-b-P S(5 \% \mathrm{w} / \mathrm{v})$ than other formulations.

\section{Materials and Methods}

\section{Materials/Chemicals}

$N$-Isopropylacrylamide (NIPAM), styrene, acrylic acid (AAc), acrylamide (AAm), Cellulose triacetate (CTA), 2,2'-Azobis(2-methylpropionitrile) (AIBN), Deuterated chloroform $\left(\mathrm{CDCl}_{3}\right)$, Dimethyl sulfoxide$\mathrm{d}_{6}\left(\right.$ DMSO- $\left.\mathrm{d}_{6}\right), 1,4$-dioxane, $\mathrm{N}, \mathrm{N}$-dimethylformamide anhydrous (DMF) and Cytodex ${ }^{(\mathrm{r})} 3$ microcarrier were purchased from Sigma-Aaldrich. Dulbecco's modified Eagle's medium (DMEM), 3-[4,5-dimethylthiazol-2yl]-2,5 diphenyltetrazolium bromide (MTT), fetal bovine serum (FBS), penicillin-streptomycin, trypsin, and phosphate-buffered saline (PBS) were obtained from GIBCO Invitrogen Corp.

\section{Synthesis of PNIPAm based copolymers}

In order to improve the LCST of PNIPAm towards body temperature, it was copolymerized with hydrophilic acrylic acid (AAc) or acrylamide (AAm) at different ratios. Because, as the hydrophilic component in the copolymer increased, the LCST value could increase.

\section{Synthesis of poly (NIPAm-co-AAc)}

Poly(N-isopropylacrylamide)-co-poly (acrylic acid) (PNIPAm-co-AAc) was synthesized by reversible addition fragmentation transfer (RAFT) using AIBN as initiator. Briefly, $3.36 \mathrm{~g}(29.7 \mathrm{mmol}) \mathrm{NIPAm}, 21.62 \mathrm{mg}$ $(0.3 \mathrm{mmol})$ AAc, $83.81 \mathrm{mg}(0.3 \mathrm{mmol}) \mathrm{CTA}$ and $9.85 \mathrm{mg}(0.06 \mathrm{mmol})$ AIBN were dissolved in $30 \mathrm{~mL}$ of 1,4-dioxane in a $50 \mathrm{~mL}$ round bottom flask. After the mixture was purged with nitrogen for $30 \mathrm{~min}$, it was stirred at a temperature of $70 \mathrm{degC}$ for inducing polymerization (Scheme 2a). The reaction was carried out 
for $24 \mathrm{~h}$ and the crude product was purified by precipitating in cold diethyl ether. The residual solvents were removed by drying overnight under a vacuum (45 degC).

\section{Synthesis of poly (NIPAm-co-AAm)}

To synthesize poly (N-isopropylacrylamide)-co-poly (acrylamide) (PNIPAm-co -AAm), $3.36 \mathrm{~g}$ (29.7 mmol) NIPAm, $205.31 \mathrm{mg}(1 \mathrm{mmol})$ AAm and $27.2 \mathrm{mg}(0.1 \mathrm{mmol})$ CTA was added into $25 \mathrm{~mL}$ round bottom flask and dissolved with $9.8 \mathrm{~mL}$ of 1,4-dioxane. After $0.2 \mathrm{~mL}$ of AIBN solution in 1,4-dioxane (3.284 mg, 0.02 mmol) was added, the mixture was purged with nitrogen in an ice-water bath for $30 \mathrm{~min}$. Subsequently, the solution was stirred for $24 \mathrm{~h}$ at a temperature of $70 \operatorname{deg} \mathrm{C}$ for polymerization and then the flask was submerged into liquid nitrogen to terminate the reaction (Scheme 2b). Finally, the crude product was precipitated in cold diethyl ether to remove the unreacted RAFT agent and the residual monomers. The copolymer was dried under a vacuum oven overnight.

\section{Synthesis of poly (NIPAm-co-AAc)- $b$-polystyrene}

To enhance cytodex 3 microcarrier coating efficiency and cell anchoring, Styrene was further block copolymerized with poly (NIPAm-co-AAc) or poly (NIPAm-co-AAm) was further copolymerized with hydrophobic styrene monomer. Therefore, poly (NIPAm-co -AAc)- $b$-polystyrene (NIPAm- $c o-A A c-b$-PS) was synthesized by reversible addition fragmentation transfer (RAFT) reaction as follow. First, $1 \mathrm{~g}(0.125 \mathrm{mmol})$ PNIPAm- $c o$-AAc, $130.19 \mathrm{mg}(1.25 \mathrm{mmol})$ styrene and $4.11 \mathrm{mg}(0.025 \mathrm{mmol})$ AIBN were dissolved with 10 $\mathrm{mL}$ DMF. Then, the mixture was introduced into a $25 \mathrm{~mL}$ round bottom flask and purged with nitrogen for $30 \mathrm{~min}$. The reaction was carried out at $70 \mathrm{deg} \mathrm{C}$ with continuous stirring for $24 \mathrm{~h}$. The copolymer was purified through precipitation in cold diethyl ether and the unreacted RAFT agent and the residual monomers were removed along with the supernatants (Scheme 2c). Finally, the residual solvents were removed from the precipitate polymer using vacuum oven at a temperature of $45 \operatorname{deg} \mathrm{C}$ overnight.

\section{Synthesis of poly (NIPAm-co-AAm)-b- polystyrene}

Similarly, poly (NIPAm-co-AAm)-b- polystyrene (PNIPAM-co-AAm- $b$-PS) was prepared via RAFT polymerization in the presence of AIBN initiator. In brief, $1 \mathrm{~g}(0.125 \mathrm{mmol})$ PNIPAm-co-AAm, $130.19 \mathrm{mg}(1.25$ $\mathrm{mmol})$ styrene and $4.11 \mathrm{mg}(0.025 \mathrm{mmol})$ AIBN were dissolved in $10 \mathrm{~mL}$ DMF and the mixture was poured into a $25 \mathrm{~mL}$ round bottom flask. Then, the mixture was purged with nitrogen for $30 \mathrm{~min}$, and then heated to $70 \mathrm{degC}$ to induce polymerization (Scheme $2 \mathrm{~d}$ ). After $24 \mathrm{~h}$, the reaction was terminated by immersing the flask into cold water bath and then the copolymer was purified by precipitating in cold diethyl ether. Ultimately, the copolymer was dried under vacuum oven overnight to remove the residual solvents. After all, the successful polymerization of series of copolymers were confirmed using ${ }^{1} \mathrm{HNMR}$, and GPC analytical techniques.

\section{LCST turbidity measurement}

The turbidity or transmittance of polymer solution was measured at $500 \mathrm{~nm}$ with a UV-visible spectrophotometer (JASCO-V-650). Series of PNIPAm based copolymer solutions (0.1 wt. \%) were prepared in distilled water and the UV-vis absorbances of the polymer solutions were measured from 10 to $50 \mathrm{degC}$. The temperature was controlled by Water Thermostatted Cell Holder with Stirrer (STR-773) and each experiment was started with an initial stabilization at $10 \mathrm{degC}$ for $10 \mathrm{~min}$ and the heating rate was $1 \mathrm{deg} \mathrm{C} / \mathrm{min}$. The $50 \%$ of visible light transmittance curve was considered as the LCST transition temperature.

\section{Thin film preparation and characterization}

Copolymer films were fabricated through spin coating. Initially different concentration of polymers in ethanol $(5 \% \mathrm{w} / \mathrm{v}, 10 \% \mathrm{w} / \mathrm{v}$ and $20 \% \mathrm{w} / \mathrm{v})$ were prepared and $150 \mu \mathrm{L}$ aliquot of an ethanolic polymer solution was depositing onto a slowly spinning SPL coverslip $(25 \mathrm{~mm} \varnothing),(300 \mathrm{rpm})$ on a Yotec SC-80R ${ }^{+}$spin coater. The final spin speed was $4000 \mathrm{rpm}$, for $30 \mathrm{~s}$. After the polymer solutions coated on the coverslips, all coverslips were housed in $35 \mathrm{~mm}$ petri dishes and drying in a vacuum oven at $40^{\circ} \mathrm{C}$ overnight to ensured that the residual solvent was eliminated (Fig.1 ). 
For SEM analysis of the film thickness, the silicon wafer was used as the substratum and it was coated with platinum before SEM imaging has been taken. The alpha-step profilometer (Surfcorder ET3000) which uses a diamond-made sharp probe to scan the surface of objects at a speed of $0.1 \mathrm{~mm} / \mathrm{s}$ and stylus force of $5 \mathrm{gm}$ was also employed to measure the thickness of the prepared polymer films. The variation of height during scanning was detected and recorded with a conductive sensor and used to estimate the thickness of the film with an accuracy of $0.1 \mathrm{~nm}$.

\section{Contact angle measurement}

The contact angle was determined by Drop Shape Analyzer using Sindatek Instruments (Model 100E). First, the coverslip was placed on the stage and the whole system was adjusted at room temperature. Then, the DI water was kept at $37^{\circ} \mathrm{C}$, which is above the LCST of the polymers we intended to measure.

\section{Cell viability test (MTT Assay)}

The biocompatibility of the copolymers was evaluated by assessing RAW264.7 cell viability which was determined using MTT cell proliferation assay following the protocols of the previous studies (Birhan et al., 2020; Fentahun Darge et al., 2021). Briefly, RAW264.7 macrophages were seeded on 96-well plates at a density of $1 \times 10^{4}$ cells/well in complete DMEM medium supplemented with $10 \%$ FBS, and $1 \%$ streptomycin and maintained in a humidified incubator at $37{ }^{\circ} \mathrm{C}$ under $5 \% \mathrm{CO}_{2}$. After $24 \mathrm{~h}$, the medium was replenished with fresh medium containing copolymers at different concentration (ranged from 0.0005 to $5 \mathrm{mg} / \mathrm{mL}$ ) and incubated at $37{ }^{\circ} \mathrm{C}$ for $24 \mathrm{~h}$. Then, the cells were washed with PBS (pH 7.4) and added MTT reagent to each well at a concentration of $1 \mathrm{mg} / \mathrm{mL}$ of medium. Following $4 \mathrm{~h}$ incubation, the MTT containing medium was replaced with $150 \mu \mathrm{L}$ DMSO to each well and the plates were incubated at $37^{\circ} \mathrm{C}$ for 25 min until all the formazan crystals were dissolved. Finally, the absorbance of reduced formazan in each well (triplicate samples) was measured with microplate reader at $570 \mathrm{~nm}$ and the cell viability was estimated using the following equation (equation 1).

$$
\text { Cell viability }(\%)=\frac{\text { Absorbance of Test }}{\text { Absorbance of control }} x 100(1)
$$

\section{Cell attachment and thermally induced detachment from polymer films and polymer coated cytodex 3 microcarriers}

The cellular attachment on the surface of thermosensitive copolymer films coated on coverslips or cytodex 3 microcarriers and their subsequent thermally induced detachment was examined using RAW 264.7 cells. First the coverslips were coated with copolymer solution and then RAW 264.7 cells were seeded $\left(4 \times 10^{4} \mathrm{cells} / \mathrm{cm}^{2}\right)$ on the copolymer films and bare coverslips as a control group followed by incubation for $48 \mathrm{~h}$ at a humidified atmosphere $\left(95 \%\right.$ air and $\left.5 \% \mathrm{CO}_{2}\right)$ at $37{ }^{\circ} \mathrm{C}$. Since the LCST of the copolymers is above $37{ }^{\circ} \mathrm{C}$, keeping the cells at this temperature allowed to be attached on it. Similarly, for suspension cell cultures (3D cell culture) on Cytodex 3 microcarriers or copolymer film coated Cytodex 3 microcarriers, RAW 264.7 cells were used. First the Cytodex 3 microcarriers were hydrated and coated with copolymer solution as follow: Cytodex 3 was hydrated in PBS $(1 \mathrm{~g} / 100 \mathrm{~mL})$ at room temperature and 2 to 3 drops of Tween 80 was added. After $3 \mathrm{~h}$, the supernatant of the Cytodex 3 was decanted and washed by fresh PBS (50 mL/g of Cytodex 3$)$ for 3 min. Then, the Cytodex 3 was sterilized in an autoclave at $115^{\circ} \mathrm{C}, 15$ psi (pounds per square inch) for 30 min. Following the removal of the supernatant, the cytodex 3 was briefly rinsed with warm culture medium (50 $\mathrm{mL} / \mathrm{g}$ of Cytodex 3$)$ and then mixed with the polymer solution $(10 \% \mathrm{w} / \mathrm{v}$ medium) for $24 \mathrm{~h}$. Finally, it was transferred into the culture medium $(3 \mathrm{mg} / \mathrm{mL}$ medium). Prior to use, the supernatant was discarded and the microcarriers were transferred to the new culture medium $(33 \mathrm{~mL})$ at $37^{\circ} \mathrm{C}$ in the spinner flask. Then, the cells were transferred into the spinner flask $\left(4 \times 10^{5}\right.$ cells $\left./ \mathrm{mL}\right)$ and spinner flask was gently agitated at 25 rpm for 2-3 days. At every 2 days, the agitation was temporarily stopped for $5 \mathrm{~min}$ to allow the microcarriers to be precipitated and about $66 \%$ of the culture supernatant was replenished with fresh medium.

To perform thermally induced cellular detachment from the polymer film coated coverslips or microcarriers, the cells were put at a low temperature $\left(20^{\circ} \mathrm{C}\right)$ for different time intervals $(0,10$, and $20 \mathrm{~min})$ and compared the effective detachment of cells. The cells were also re-seeded after harvesting to assess the functionality of 
cells after thermally induced detachment. Films were sterilized under UV light for $12 \mathrm{~h}$ prior to cell culture experiments.

\section{Results and Discussion \\ Synthesis of PNIPAm-AAc and PNIPAm-AAc copolymers}

Poly (NIPAm) is a thermosensitive polymer which exhibits LCST behavior in response to temperature change. However, its LCST value is lower than body temperature which ranges from 30 to 32 degC, irrespective of polymer concentration. In order to raise the LCST of the polymer, frequently hydrophilic polymers are incorporated in the copolymer or increase the proportion of hydrophilic to hydrophobic components in the copolymer and have been shown to elevate the LCST of PNIPAm (Jain, Vedarajan, Watanabe, Ishikiriyama, \& Matsumi, 2015; Koc \& Alveroglu, 2016; Osvath \& Ivan, 2017). Therefore, in this study, NIPAm was copolymerized with hydrophilic acrylic acid (AAc) or acrylamide (AAm) at different ratios to prepare a thermo-responsive PNIPAm- $c o$-AAc with optimized LCST value near to body temperature. It was synthesized by reversible addition fragmentation chain transfer polymerization (RAFT) which is important for getting the desired polymers owing to a higher control on the final molecular characteristics, like polydispersity and molecular weight (scheme 2a ) (Garcia-Penas et al., 2019). The successful polymerization of the copolymer was confirmed using ${ }^{1} \mathrm{H}$ NMR spectroscopy. As shown in Fig.2a , the characteristic signals at ? $1.21(\mathrm{~A})$ and $3.95(\mathrm{~B}) \mathrm{ppm}$ are attributed to the methyl and methine protons of NIPAm, respectively. Additionally, the signals at ? $2.07(\mathrm{C})$ and $1.63(\mathrm{D}) \mathrm{ppm}$ which came from the methine and methylene protons of the main polymer chain, respectively, verified the successful preparation of the copolymer.

Similarly, NIPAm was copolymerized with acrylamide (AAm) to prepare PNIPAm-co-AAm and optimized the LCST of PNIPAm near to body temperature for intended applications in cell attachment/detachment. The characteristic peaks of ${ }^{1} \mathrm{H}$ NMR spectrum inFig.2b below confirmed the successful preparation of PNIPAm- $c o-A A m$. The signals at ? 3.82(a) and 1.04(b) ppm were attributed to the methine protons and methyl protons of NIPAm, respectively. In addition to the characteristic peaks of methine and methylene protons of the main chain of the copolymer at ? 1.93 (c) and 1.41 (d), respectively, the signal at ? 7.29(e) ppm which was attributed to the amide protons of acrylamide further proved the effective copolymerization of PNIPAm- $c 0$-AAm.

\section{LCST measurement of the copolymers}

The LCST of poly (NIPAm- $c o-A A c)$ and poly (NIPAm- $c o-A A m)$ were assessed with turbidimetric analytic method. The turbidity or transmittance of the copolymer solution was measured at $500 \mathrm{~nm}$ with a UV-vis spectrophotometer (JASCO-V-650). Polymer solutions (0.1 wt. \%) were prepared in distilled water and the UV absorbances were measured from 10 to $50 \mathrm{degC}$. The solutions were kept in refrigerator at $4 \operatorname{deg} \mathrm{C}$ overnight before measurement. The LCST transition temperature of the copolymer solutions were explained by determining the cloud point at $50 \%$ of transmittance of incident visible light which is the most direct way to observe LCST behavior. When the temperature of the solution raised above the transition temperature, the copolymer aggregated and exhibit a cloudy appearance or phase separation of the solution. On the other hand, when the solution temperature reduced below LCST, water-polymer interaction increased by hydrogen bonding and form transparent solution, whereas at a temperature of above LCST, the polymerpolymer hydrophobic interactions increased and the hydrogen bonds were broken, subsequently polymer globules were formed and the solution became cloudy (Fig. 3 ) (Sun et al., 2019). Thus, the turbidity was measured from lower to higher temperature and $50 \%$ of transmittance was used for deciding LCST of the copolymer solutions.

As shown in Fig . $\mathbf{4} \mathbf{a} \& \mathbf{b}$, when the ratio of acrylic acid or acrylamide that copolymerized with NIPAm were increased, the LCST temperature of the copolymer was shifted to the higher values. This is due to the hydrophilic nature of acrylic acid and acrylamide and thus the copolymer solution requires higher temperature for phase transmission and enabled the copolymer to be aggregated (Katsumoto, Tanaka, Sato, \& Ozaki, 2002). The cloud point of PNIPAm-co-AAc 1 , PNIPAm-co-AAc $c_{3}$, and PNIPAm-co-AAc was $_{5}$ shifted to $29.5 \mathrm{deg} C, 30 \mathrm{deg} C$ and $32 \mathrm{deg}$, respectively, indicating that increasing the ratio of the acrylic acid 
increases the LCST of the copolymer solution. The suffix,1, 3 and 5 in the copolymer denoted to refer the ratio of AAc to NIPAm (1:1, 3:1 and 5:1, respectively). Similarly, the cloud point of PNIPAm-co-AAm 1 , PNIPAm- $c o-\mathrm{AAm}_{3}$ and PNIPAm- $c o-\mathrm{AAm}_{5}$ was shifted to $28 \mathrm{degC}, 30 \mathrm{degC}$ and $32 \mathrm{degC}$, where the LCST of the copolymer solution increased with increase the ratio of the acrylamide in the copolymer.

Furthermore, we compared the intensity of ${ }^{1} \mathrm{H}$ NMR signals of the copolymer solutions at $25 \mathrm{degC}$ (standard) and $37 \mathrm{degC}$ in $\mathrm{D}_{2} \mathrm{O}$ to verify the LCST behavior of the copolymer. As depicted in Fig. 4c ${ }^{1} \mathrm{H}$ NMR signal intensity was relatively lower at $37 \mathrm{degC}$ than the $25 \mathrm{degC}{ }^{1} \mathrm{H}$ NMR signals. Since the polymer was aggregated at $37 \mathrm{degC}$, its ${ }^{1} \mathrm{H}$ NMR signal intensity was reduced as compared with $25 \mathrm{degC}{ }^{1} \mathrm{H}$ NMR signals and this phenomenon proofed the LCST property of the copolymer.

\section{Synthesis of PNIPAm-co-AAc- $b$-PS and PNIPAm-co-AAm- $b$-PS}

Once we optimized the LCST of NIPAm- $c o$-AAc or NIPAm- $c o$-AAcm copolymers near to body temperature via copolymerizing NIPAm with AAc or AAm, it was further copolymerized with styrene by RAFT and obtained poly (NIPAm- $c o$-AAc)- $b$-polystyrene (PNIPAm - $c o$-AAc- $b$-PS) or poly (NIPAm- $c o$-AAm)$b$-polystyrene (PNIPAM-co -AAm- $b$-PS), respectively (Scheme 2c \&d ). The presence of polystyrene enhanced the coating efficiency of the copolymers on the cytodex 3 microcarriers through hydrophobic interaction. Incorporation of polystyrene in either PNIPAm- $c o$-AAc or PNIPAm- $c o$-AAm also improved cellular attachment where serum proteins from culture medium could be adsorbed on the surface of polystyrene and further used for anchoring cells on it (Akiko Yamamoto, 2000; Clauder et al., 2020; John G. Steele, 1993; Zeiger, Hinton, \& Van Vliet, 2013). Hence, we prepared the copolymers as per the protocols and the products were confirmed by ${ }^{1}$ HNMR spectroscopy. As shown on Fig.5a, the ${ }^{1} \mathrm{H}$ NMR signals at ? 1.04 (A) and 3.84 (B) ppm were attributed to the methyl and methine protons of NIPAm, respectively. The signals at ? $1.96(\mathrm{C})$ and 1.46 (D) ppm are attributed to the methine and methylene protons from the main chain of PNIPAm, respectively, proved the successful polymerization. On top of these, the presence of a signal at 7.19 (E) ppm represented the aromatic protons of polystyrene which further verified the polymerization of PNIPAm - $c o$-AAc- $b$-PS copolymer.

Likewise, Fig. 5b below illustrated the ${ }^{1} \mathrm{H}$ NMR spectrum of PNIPAm- $c o-A A m-b$-PS where the signals at ? 3.82(a) and 1.03(b) ppm indicated the methine and methyl protons of NIPAm, respectively. The characteristic peak at 7.32(e,f) ppm was also due to the amide protons and aromatic protons of acrylamide (AAm) and polystyrene (PS), respectively, further proved the formation of PNIPAm- $c o-A A m-b$-PS copolymer.

The molecular weight obtained from GPC (Table 1 ) also used to determine the successful preparation of the above copolymers. From the result, we could observe that the molecular weights of PNIPAm- $c o-A A c-b$ -PS and PNIPAm- $c o$-AAm- $b$-PS were significantly higher than the PNIPAm- $c o$-AAc and PNIPAm- $c o$ -AAm, respectively, suggested an effective polymerization with styrene.

\section{Preparation of polymer films and measurement of the thickness}

The thickness of the films prepared from spin-coated PNIPAm- $c o$-AAc- $b$-PS and PNIPAm-co-AAm- $b$-PS at different concentration $(5 \% \mathrm{w} / \mathrm{v}, 10 \% \mathrm{w} / \mathrm{v}$ and $20 \% \mathrm{w} / \mathrm{v})$ on coverslips were measured using alpha-step profilometer and summarized inTable 2 . The surface was crosscut by needle and measured the broken side of the surface to detrend the thickness of the film. SEM imaging was also used to analyze the thickness of the copolymer films. The solution of the copolymers at different concentration was spin-coated on silicon wafer. In the meanwhile, copolymer coated silicon wafer was broken and placed vertically on the carrier to measure the thickness of the film with SEM imaging. The value of cross-sectional thickness of the films obtained from SEM measurement are also shown inTable $\mathbf{2}$ and the corresponding SEM images are illustrated inFig. 6 . As we realized from the results, in all cases the film thickness was directly proportional with polymer concentration which was almost doubling as we increased the concentration of copolymer solutions from $5 \%$ to $10 \%$ and 20\%. Moreover, the thickness of PNIPAm- $c o$-AAm- $b$-PS films were much thinner than PNIPAm$c o$-AAc- $b$-PS films in each polymer concentrations. This might be attributed to their different molecular weights that PNIPAm-co-AAc-b-PS had higher molecular weight $(\mathrm{Mn}=9064 \mathrm{~g} / \mathrm{mol})$ than PNIPAm- $c o$-AAc- $b$ -PS $(\mathrm{Mn}=7260)$. As the molecular weight increases, the polymer solution becomes more viscous and hinders 
the fluid to flow during spin couating which in turn significantly affect the final thickness and morphology of the polymer films (Na, Kang, \& Park, 2019; Reid et al., 2018).

\section{Water contact angle}

The value of contact angle of the coated films is an indicator of the hydrophilicity of the polymer surface. The polymer with water contact angle of less than 90deg is considered as hydrophilic while above 90deg is hydrophobic (Vazirinasab, Jafari, \& Momen, 2018). The contact angle for spin-coated PNIPAm-co -AAc- $b$ -PS and PNIPAm- $c o$-AAm- $b$-PS copolymer films with different concentration are summarized inTable 3 . Generally, cells can attach and grow on hydrophobic substrates, while they are resistant to attaching on very hydrophilic substrates. Because the water associating with the hydrophilic substrates could prohibit protein adsorption and prevent subsequent cell attachment on the surface (Elbert \& Hubbell, 1996). Although, cells are able to grow on hydrophobic substrates, several studies realized that neither extremes are conducive for cell attachment and growth. In other words, super-hydrophilic surface (contact angle $<5 \mathrm{deg}$ ) and superhydrophobic surface (contact angle $>150 \mathrm{deg}$ ) are not suitable for cell attachment and growth. This is due to the fact that hydrophilicity of the substrate surface affects the binding strength, conformation and type of proteins adsorbed from the culture medium, which in turn determine cell attachment and growth. Only on moderately hydrophilic substrates with a water contact angle of approximately 55deg achieved optimal cell attachment and growth (Cai et al., 2020; Lee, Khang, Lee, \& Lee, 1998). In this regard, the contact angle of PNIPAm based copolymer films were relatively ideal for cell attachment (Lee et al., 1998; Sumner et al., 2004). Particularly, the contact angle of PNIPAm-co -AAc (5\%), PNIPAm-co-AAc (10\%) and PNIPAm-co -AAm- $b$-PS (20\%) exhibit a water contact angle of 53.0deg, $53.8 \mathbf{d e g}$ and $46.6 \mathbf{d e g}$, respectively, which were closer to the ideal contact angle for cell attachment and growth compared with other formulations (Table 3 \& Fig.7 ).

\section{Cytotoxicity test (MTT assay)}

Biocompatibility of the copolymer is the most important feature to be used as a cell attachment substrate. Thus, the potential toxicity of PNIPAm- $c o$-AAc- $b$-PS and PNIPAm- $c o-A A c-b$-PS copolymers have been evaluated on RAW264.7 cell lines using in vitro MTT dye reduction assay (Fentahun Darge et al., 2021; Sakulaue et al., 2018). The toxicity of the copolymers was performed by quantifying the viability of cells treated with copolymers (PNIPAm- $c o$-AAc- $b$-PS and PNIPAm- $c o$-AAc- $b$-PS) for $24 \mathrm{~h}$ at a concentration range of 0.0005 to $5 \mathrm{mg} / \mathrm{mL}$. As shown inFig. 8 , The in vitro cytotoxicity test revealed that the copolymer exhibited negligible cytotoxicity towards RAW264.7 cells up to a concentration of $5 \mathrm{mg} \mathrm{ml} / \mathrm{L}$, suggested that the material is biocompatible for the application of cell attachment matrix.

\section{Cell attachment and thermal-induced detachment}

After RAW 264.7 cells were cultured on bare coverslips and copolymer coated coverslips $\left(4 \times 10^{4}\right.$ cells $\left./ \mathrm{cm}^{2}\right)$ for $48 \mathrm{~h}$, cell confluent was monitored under microscope. According to microscopic observation (Figure 9 a, b, \& c ), after $48 \mathrm{~h}$, RAW 264.7 cells were already grown well on the surface of both bare coverslips and copolymer coated coverslips and the cell confluent was almost $>80 \%$ which revealed that the copolymers are non-toxic to be used as a substrate for cell proliferation and thermo-induced cell detachment. Moreover, from microscopic examination, we realized that moderately dense cells were observed in PNIPAm- $c o-A A m-b$ -PS films which may be due to the presence of surface positive charges derived from amide groups enhanced cell adhesion (Guo et al., 2016; Hoshiba, Yoshikawa, \& Sakakibara, 2018). So as to achieve thermal-induced cell detachment from the control group (bare coverslips) or polymer film coated coverslips, the medium of cells incubated for $48 \mathrm{~h}$ was replenished with cold PBS (20degC) and kept at 20degC. Then the cell detachment was observed at 0 min (immediately after cold PBS was added), 10 min and 20 min and cell images have been taken for each corresponding times. Immediately after the addition of cold PBS, there was no cell detachments observed in either the control group or polymer coated coverslips. However, after $10 \mathrm{~min}$ in refrigerator $(20 \mathrm{deg}$ ), mass of aggregated cells was floating in polymer coated coverslips, while very few single cells were detached in the control group. Therefore, it was kept in 20degC for additional $10 \mathrm{~min}$ and we have observed a well dispersed detached cells in polymer coated coverslips but not in the 
control group. Predominantly, PNIPAm- $c o-A A m-b-P S(5 \% \mathrm{w} / \mathrm{v})$ showed relatively substantial number of cell detachment than other formulations. This might be due to relatively more hydrophilic nature of PNIPAm- $c o-A A m-b-P S(5 \% \mathrm{w} / \mathrm{v})$ which exhibit smaller contact angle (40.1deg) and favored more cell detachments than other formulations with higher contact angles (Fig. 9b ). Comparatively more hydrophilic polymers that contain polar functional groups provide surface hydration through strong hydrogen bonding with water molecules in aqueous solution. Therefore, a water hydration barrier formed between the polymer and hydrogen molecules could determine the conformation and type of essential proteins adsorbed on the polymer surface and subsequently affect proper cell adhesion or the firmness of cell attachment (Chen, Yan, \& Zheng, 2018; de los Santos Pereira et al., 2016; Leng et al., 2015; Wei, Zhang, Li, Zhang, \& Bi, 2015). As a result, PNIPAm- $c o$-AAm- $b$-PS at a concentration of $5 \% \mathrm{w} / \mathrm{v}$ provided maximum cell detachment and was chosen to coat cytodex 3 microcarriers for further $3 \mathrm{D}$ cell culturing and thermal-induced cell detachment from the microcarriers.

\section{Characterization of PNIPAm-co-AAm- $b$-PS coated microcarriers}

Attachment and detachment of cells to and from microcarriers are basic concerns that determined the final cell productivity and quality. The surface of microcarrier is the most important feature that determined cell attachment and stimuli responsive detachment of cells from the microcarriers. Therefore, surface modification or coating of microcarriers with smart polymers helps for cell anchoring and non-enzymatic (stimuli responsive) detachment (Sorour Derakhti, Seyed Hamid Safiabadi-Tali, Ghassem Amoabediny, \& Mojgan Sheikhpour, 2019; A.-C. Tsai, R. Jeske, X. Chen, X. Yuan, \& Y. Li, 2020). Thus, a thermosensitive and biocompatible PNIPAm- $c o$-AAm- $b$-PS $(5 \% \mathrm{w} / \mathrm{v})$ copolymer was used to coat cytodex 3 microcarrier for enhancing cell anchoring and thermal-induced cell detachment. The copolymer coated microcarrier (cytodex 3) was confirmed by FT-IR spectra (Figure 10c ). Both the sharp signal of N-H stretching $\left(3300 \mathrm{~cm}^{-1}\right)$ in pNIPAm- $c o$-AAm- $b$-PS and the broad signal of O-H stretching $\left(3400 \mathrm{~cm}^{-1}\right)$ in cytodex 3 were changed in the coated cytodex3, indicating the successful coating of the microcarrier with pNIPAm-co-AAm- $b$-PS. Moreover, the occurrence of very sharp signal at $1640 \mathrm{~cm}^{-1}$ in coated cytodex 3 was due to the specific signal of amide bending $\left(1530 \mathrm{~cm}^{-1}\right)$ from pNIPAm- $c o$-AAm- $b$-PS further confirmed the coating of microcarrier.

The morphology of cytodex 3 and polymer coated cytodex 3 were also examined with SEM imaging. As shown in Figure $10 \mathbf{a} \& \mathbf{b}$, the surface of uncoated cytodex 3 is very smooth while the surface morphology of the coated microcarriers were rough and some wrinkles were observed. The reason of the wrinkles is probably caused by the process of sample preparation, which should be dehydrate before SEM measurement. The polymer shrieked and resulted wrinkled surface of on the coated Cytodex 3.

Cell attachment and detachment from thermosensitive polymer coated cytodex 3 microcarrier

RAW 264.7 cells were cultured on bare cytodex 3 and poly (NIPAm- $c o-A A m)-b$-PS ( $5 \% \mathrm{w} / \mathrm{v}$ ) coated cytodex 3 in spinner flask. The microscopic image of cells shown in Figure 11 had no difference in cell adhesion and morphology between commercially available bare cytodex 3 and polymer coated cytodex 3 microcarrier during $48 \mathrm{~h}$ of incubation period. This suggested that the NIPAm-co-AAm- $b-P S(5 \% \mathrm{w} / \mathrm{v})$ coated on the cytodex 3 microcarrier surface did not affect cell attachment or viability of cells. However, interestingly a reduction of the temperature from $37 \mathrm{deg} \mathrm{C}$ to $20 \mathrm{deg} \mathrm{C}$ induced a significant cell detachment from coated cytodex 3 microcarriers within 20 min (Figure 12). The thermo-responsive behavior of PNIPAm-co-AAm- $b$ -PS which could have hydrophobic to hydrophilic phase transition as temperature reduced below its LCST enhanced cellular detachment (Nguyen et al., 2019; L. Yang, Fan, Zhang, \& Ju, 2020). Therefore, unlike the bare cytodex 3 , thermosensitive coated cytodex 3 microcarriers showed spontaneous cell detachments with reducing temperature lower than LCST. This temperature induced cell detachment strategy might be essential to harvest adequate viable cells with preserved cell features and functionality that are mostly lost during enzymatic cell dissociation (Kim et al., 2020; Sakulaue et al., 2018).

\section{Conclusion}

PNIPAm based thermo-responsive block copolymers were successfully synthesized and the LCST of PNIPAm was optimized near to body temperature by copolymerizing with hydrophilic AAc and AAm to be used for cell 
attachment and thermal-induced cell detachment. The UV-Vis spectroscopy measurement of turbidity with controlling the temperature confirmed that increasing the ratio of hydrophilic AAc or AAm copolymerized with PNIPAm, raise the LCST value ( $\sim 34 \mathrm{degC})$. PNIPAm-co -AAc and PNIPAm- $c o$-AAm were further copolymerized with styrene for cell anchoring and enhancing coating on cytodex 3 microcarrier. The in vitro cytotoxicity study against RAW264.7 cells revealed that PNIPAm based copolymers were biocompatible up to a concentration of $5 \mathrm{gm} / \mathrm{ml}$ and can be dissolved in ethanol for spin-coating on coverslip to prepare thin films. The thickness of the copolymers film and water contact angle were measured and have moderately hydrophilic nature which was suitable for cell culturing. Therefore, the RAW264.7 cells were successfully attached and proliferated on the polymer films. Among different formulations, the PNIPAm-co -AAm- $b$ -PS $(5 \% \mathrm{w} / \mathrm{v})$ copolymer films showed relatively better thermal-induced cell detachment and thus chosen to coat the microcarrier (Cytodex 3) for further 3D cell culturing. Hence, following coating of cytodex 3 microcarriers with PNIPAm-co -AAm- $b$-PS (5\% w/v), RAW264.7 cells were properly attached and grown on it and subsequently abundant cells were detached within $20 \mathrm{~min}$ in response to reduction of temperature (20 degC). After detachments, the cells were reseeded and abled to attach on the surface again without noticeable difference compared with the control group.

Apparently, PNIPAm- $c o$-AAc- $b$-PS and PNIPAm- $c o$-AAm- $b$-PS copolymers were perfectly prepared and was verified as a suitable substrate for cell culturing and can be used for thermo-responsive cell dissociations to alleviate enzyme associated cell damage during cell harvesting.

\section{Acknowledgement}

The authors would like to thank the Ministry of Science and Technology, Taiwan (MOST105-2221-E-011133-MY3 and 105-2221-E-011-151-MY3) for providing financial support.

\section{Declaration of competing interest}

We declare that there is no conflict of interest.

\section{References}

Akiko Yamamoto, S. M., Norio Maruyama, Masae Sumita. (2000). Quantitative evaluation of cell attachment to glass, polystyrene, and fibronectin- or collagen-coated polystyrene by measurement of cell adhesive shear force and cell detachment energy. J Biomed Mater Res., 50 , 114-124.

Birhan, Y. S., Darge, H. F., Hanurry, E. Y., Andrgie, A. T., Mekonnen, T. W., Chou, H. Y., . . . Tsai, H. C. (2020). Fabrication of Core Crosslinked Polymeric Micelles as Nanocarriers for Doxorubicin Delivery: Self-Assembly, In Situ Diselenide Metathesis and Redox-Responsive Drug Release. Pharmaceutics, 12 (6).

Cai, S., Wu, C., Yang, W., Liang, W., Yu, H., \& Liu, L. (2020). Recent advance in surface modification for regulating cell adhesion and behaviors. Nanotechnology Reviews, 9 (1), 971-989.

Chen, L., Yan, C., \& Zheng, Z. (2018). Functional polymer surfaces for controlling cell behaviors. Materials Today, 21 (1), 38-59.

Clauder, F., Zitzmann, F. D., Friebe, S., Mayr, S. G., Robitzki, A. A., \& Beck-Sickinger, A. G. (2020). Multifunctional coatings combining bioactive peptides and affinity-based cytokine delivery for enhanced integration of degradable vascular grafts. Biomater Sci, 8 (6), 1734-1747.

de los Santos Pereira, A., Sheikh, S., Blaszykowski, C., Pop-Georgievski, O., Fedorov, K., Thompson, M., \& Rodriguez-Emmenegger, C. (2016). Antifouling Polymer Brushes Displaying Antithrombogenic Surface Properties. Biomacromolecules, 17 (3), 1179-1185.

Derakhti, S., Safiabadi-Tali, S. H., Amoabediny, G., \& Sheikhpour, M. (2019). Attachment and detachment strategies in microcarrier-based cell culture technology: A comprehensive review. Mater Sci Eng C Mater Biol Appl, 103 , 109782. 
Derakhti, S., Safiabadi-Tali, S. H., Amoabediny, G., \& Sheikhpour, M. (2019). Attachment and detachment strategies in microcarrier-based cell culture technology: A comprehensive review. Materials Science and Engineering: C, 103, 109782.

Elbert, D. L., \& Hubbell, J. A. (1996). Surface Treatments of Polymers for Biocompatibility. Annual Review of Materials Science, 26 (1), 365-394.

Fentahun Darge, H., Yibru Hanurry, E., Simegniew Birhan, Y., Worku Mekonnen, T., Tizazu Andrgie, A., Chou, H.-Y., . . . Tsai, H.-C. (2021). Multifunctional drug-loaded micelles encapsulated in thermo-sensitive hydrogel for in vivo local cancer treatment: Synergistic effects of anti-vascular and immuno-chemotherapy. Chemical Engineering Journal, $406,126879$.

Garcia-Penas, A., Biswas, C. S., Liang, W., Wang, Y., Yang, P., \& Stadler, F. J. (2019). Effect of Hydrophobic Interactions on Lower Critical Solution Temperature for Poly (N-isopropylacrylamide-co-dopamine Methacrylamide) Copolymers.Polymers, 11 (6), 991.

Guo, S., Zhu, X., Li, M., Shi, L., Ong, J. L., Janczewski, D., \& Neoh, K. G. (2016). Parallel Control over Surface Charge and Wettability Using Polyelectrolyte Architecture: Effect on Protein Adsorption and Cell Adhesion. ACS Appl Mater Interfaces, 8 (44), 30552-30563.

Hanga, M. P., \& Holdich, R. G. (2014). Membrane emulsification for the production of uniform poly-Nisopropylacrylamide-coated alginate particles using internal gelation. Chemical Engineering Research and Design, 92 (9), 1664-1673.

Higuchi, A., Ling, Q.-D., Kumar, S. S., Chang, Y., Kao, T.-C., Munusamy, M. A., . . . Umezawa, A. (2014). External stimulus-responsive biomaterials designed for the culture and differentiation of ES, iPS, and adult stem cells. Progress in Polymer Science, 39 (9), 1585-1613.

Hoshiba, T., Yoshikawa, C., \& Sakakibara, K. (2018). Characterization of Initial Cell Adhesion on Charged Polymer Substrates in Serum-Containing and Serum-Free Media. Langmuir, 34 (13), 4043-4051.

Jain, K., Vedarajan, R., Watanabe, M., Ishikiriyama, M., \& Matsumi, N. (2015). Tunable LCST behavior of poly(N-isopropylacrylamide/ionic liquid) copolymers. Polymer Chemistry, 6 (38), 6819-6825.

John G. Steele, B. A. D., Graham Johnson, and P. Anne Underwood. (1993). Polystyrene chemistry affects vitronectin activity: An explanation for cell attachment to tissue culture polystyrene but not to unmodified polystyrene. Journal of Biomedical Materials Research, 27, , 927-940

Katsumoto, Y., Tanaka, T., Sato, H., \& Ozaki, Y. (2002). Conformational Change of Poly(Nisopropylacrylamide) during the Coil-Globule Transition Investigated by Attenuated Total Reflection/Infrared Spectroscopy and Density Functional Theory Calculation. The Journal of Physical Chemistry A, 106 (14), 3429-3435.

Kim, H., Witt, H., Oswald, T. A., \& Tarantola, M. (2020). Adhesion of Epithelial Cells to PNIPAm Treated Surfaces for Temperature-Controlled Cell-Sheet Harvesting. ACS Appl Mater Interfaces, 12 (30), 33516-33529.

Koc, K., \& Alveroglu, E. (2016). Tuning the gel size and LCST of N-isopropylacrylamide nanogels by anionic fluoroprobe. Colloid and Polymer Science, 294 (2), 285-290.

Kumashiro, Y., Yamato, M., \& Okano, T. (2010). Cell attachment-detachment control on temperatureresponsive thin surfaces for novel tissue engineering. Ann Biomed Eng, 38 (6), 1977-1988.

Lee, J. H., Khang, G., Lee, J. W., \& Lee, H. B. (1998). Interaction of Different Types of Cells on Polymer Surfaces with Wettability Gradient.Journal of Colloid and Interface Science, 205 (2), 323-330.

Leng, C., Hung, H. C., Sun, S., Wang, D., Li, Y., Jiang, S., \& Chen, Z. (2015). Probing the Surface Hydration of Nonfouling Zwitterionic and PEG Materials in Contact with Proteins. ACS Appl Mater Interfaces, 7 (30), 16881-16888. 
Li, C., Qian, Y., Zhao, S., Yin, Y., \& Li, J. (2016). Alginate/PEG based microcarriers with cleavable crosslinkage for expansion and non-invasive harvest of human umbilical cord blood mesenchymal stem cells. Materials Science and Engineering: C, 64 , 43-53.

Li, N., Wang, Y., Zhao, D., Deng, B., Fan, X., \& He, X. (2021). Thermal Reversal Surface with "Sticky Tentacle" for Modulating Initial Cell Adhesion and Detachment. Materials \& Design, 199 , 109402.

Na, J. Y., Kang, B., \& Park, Y. D. (2019). Influence of Molecular Weight on the Solidification of a Semiconducting Polymer during Time-Controlled Spin-Coating. The Journal of Physical Chemistry C, 123 (28), $17102-17111$.

Nagase, K., Yamato, M., Kanazawa, H., \& Okano, T. (2018). Poly(N-isopropylacrylamide)-based thermoresponsive surfaces provide new types of biomedical applications. Biomaterials, 153 , 27-48.

Nguyen, L. T., Odeleye, A. O., Chui, C. Y., Baudequin, T., Cui, Z., \& Ye, H. (2019). Development of thermo-responsive polycaprolactone macrocarriers conjugated with Poly (N-isopropyl acrylamide) for cell culture. Scientific Reports, 9 (1), 1-11.

Osvath, Z., \& Ivan, B. (2017). The Dependence of the Cloud Point, Clearing Point, and Hysteresis of Poly(N-isopropylacrylamide) on Experimental Conditions: The Need for Standardization of Thermoresponsive Transition Determinations. Macromolecular Chemistry and Physics, 218 (4), 1600470.

Park, B. R., Nabae, Y., Surapati, M., Hayakawa, T., \& Kakimoto, M.-a. (2013). Poly (Nisopropylacrylamide)-modified silica beads with hyperbranched polysiloxysilane for three-dimensional cell cultivation. Polymer journal, 45 (2), 210-215.

Patel, N. G., \& Zhang, G. (2013). Responsive systems for cell sheet detachment. Organogenesis, 9 (2), 93-100.

Reid, J. P., Bertram, A. K., Topping, D. O., Laskin, A., Martin, S. T., Petters, M. D., . . . Rovelli, G. (2018). The viscosity of atmospherically relevant organic particles. Nature communications, 9 (1), 1-14.

Sakulaue, P., Swe, A. Y. Y., Benchaprathanphorn, K., Lertvanithphol, T., Viravaidya-Pasuwat, K., \& Siriwatwechakul, W. (2018). Improving Cell Detachment from Temperature-Responsive Poly(Nisopropylacrylamide-co-acrylamide)-Grafted Culture Surfaces by Spin Coating. ACS Omega, 3 (12), 1818118188.

Song, K., Yang, Y., Wu, S., Zhang, Y., Feng, S., Wang, H., . . . Liu, T. (2016). In vitro culture and harvest of BMMSCs on the surface of a novel thermosensitive glass microcarrier. Materials Science and Engineering: $C, 58,324-330$.

Sumner, A. L., Menke, E. J., Dubowski, Y., Newberg, J. T., Penner, R. M., Hemminger, J. C., . . . Finlayson-Pitts, B. J. (2004). The nature of water on surfaces of laboratory systems and implications for heterogeneous chemistry in the troposphere. Physical Chemistry Chemical Physics, 6 (3), 604-613.

Sun, X., Tyagi, P., Agate, S., Lucia, L., McCord, M., \& Pal, L. (2019). Unique thermo-responsivity and tunable optical performance of poly (N-isopropylacrylamide)-cellulose nanocrystal hydrogel films. Carbohydrate polymers, 208 , 495-503.

Tamura, A., Kobayashi, J., Yamato, M., \& Okano, T. (2012). Temperature-responsive poly (Nisopropylacrylamide)-grafted microcarriers for large-scale non-invasive harvest of anchorage-dependent cells. Biomaterials, 33 (15), 3803-3812.

Tamura, A., Nishi, M., Kobayashi, J., Nagase, K., Yajima, H., Yamato, M., \& Okano, T. (2012). Simultaneous enhancement of cell proliferation and thermally induced harvest efficiency based on temperatureresponsive cationic copolymer-grafted microcarriers. Biomacromolecules, 13 (6), 1765-1773.

Tsai, A.-C., Jeske, R., Chen, X., Yuan, X., \& Li, Y. (2020). Influence of microenvironment on mesenchymal stem cell therapeutic potency: from planar culture to microcarriers. Frontiers in Bioengineering and 
Biotechnology, 8, 640 .

Tsai, A. C., Jeske, R., Chen, X., Yuan, X., \& Li, Y. (2020). Influence of Microenvironment on Mesenchymal Stem Cell Therapeutic Potency: From Planar Culture to Microcarriers. Front Bioeng Biotechnol, 8 , 640. doi:10.3389/fbioe.2020.00640

Vazirinasab, E., Jafari, R., \& Momen, G. (2018). Application of superhydrophobic coatings as a corrosion barrier: A review.Surface and Coatings Technology, 341, 40-56.

Wei, Y., Zhang, J., Li, H., Zhang, L., \& Bi, H. (2015). Multifunctional copolymer coating of polyethylene glycol, glycidyl methacrylate, and REDV to enhance the selectivity of endothelial cells. Journal of Biomaterials Science, Polymer Edition, 26 (18), 1357-1371.

Yang, H. S., Jeon, O., Bhang, S. H., Lee, S.-H., \& Kim, B.-S. (2010). Suspension culture of mammalian cells using thermosensitive microcarrier that allows cell detachment without proteolytic enzyme treatment. Cell Transplantation, 19 (9), 1123-1132.

Yang, L., Fan, X., Zhang, J., \& Ju, J. (2020). Preparation and Characterization of Thermoresponsive Poly (N-Isopropylacrylamide) for Cell Culture Applications. Polymers, 12 (2), 389.

YekrangSafakar, A., Acun, A., Choi, J. W., Song, E., Zorlutuna, P., \& Park, K. (2018). Hollow microcarriers for large-scale expansion of anchorage-dependent cells in a stirred bioreactor. Biotechnology and bioengineering, 115 (7), 1717-1728.

Zeiger, A. S., Hinton, B., \& Van Vliet, K. J. (2013). Why the dish makes a difference: quantitative comparison of polystyrene culture surfaces. Acta Biomater, 9 (7), 7354-7361.

\section{Hosted file}

Schemes.pdf available at https://authorea.com/users/403663/articles/515066-preparation-ofthermosensitive-pnipam-based-copolymer-coated-cytodex-3-microcarriers-for-efficient-nonenzymatic-cell-harvesting-during-3d-culturing

\section{Hosted file}

Figuers.pdf available at https://authorea.com/users/403663/articles/515066-preparation-ofthermosensitive-pnipam-based-copolymer-coated-cytodex-3-microcarriers-for-efficient-nonenzymatic-cell-harvesting-during-3d-culturing

\section{Hosted file}

list of Tables.pdf available at https://authorea.com/users/403663/articles/515066preparation-of-thermosensitive-pnipam-based-copolymer-coated-cytodex-3-microcarriersfor-efficient-non-enzymatic-cell-harvesting-during-3d-culturing 